\title{
Evaluating and improving the efficiency of steam power plants using chillers
}

\author{
A. Hadizadeh ${ }^{1, a}$, B. Paknafs ${ }^{2}$, M. Javaherdeh ${ }^{1}$ And H. Naghashzadegan ${ }^{1}$ \\ 1 Department of Mechanical Engineering, University of Guilan, Rasht, Iran \\ 2 School of Industrial Engineering and Centre of Excellence for Intelligent Based Experimental Mechanics, \\ College of Engineering, University of Tehran, Tehran, Iran
}

Received 16 January 2016, Accepted 3 June 2016

\begin{abstract}
One of the indispensable technologies to produce electricity with high efficiency is using absorption cooling system instead of mechanical vapor compression (MVC) cooling system. In this paper, firstly heating and cooling loads are calculated for experimental model development for combined cycle power plant of Parehsar, located in province Guilan. Then according to this model, thermal energy needed for heat supporting of absorption thermal generator is computed and the appropriate chiller is chosen in order to secure cooling of model spaces. In addition, for the actual case study, the portion of generated low and high pressure steam of heat recovery steam generator (HRSG) and Turbine is investigated for the absorption chillers used in residential space cooling of power plant. Results indicate that the steam extraction of HP-Turbine approach is more effective than the other approaches for improving the power planet energy efficiency. In addition, parametric study indicates the effects of different parameters, such as steam to gas mass flow rate ratio, fraction of steam extraction from the exhaust of LP line in HRSG for the generator of absorption chillers and inlet LP and HP steam turbine temperature on the performance of present power plant. Finally, the relative advantage of using absorption cooling over mechanical vapor compression (MVC) cooling in combined cycle power plant and its role in improvement of power plant efficiency is demonstrated.
\end{abstract}

Key words: Absorption chiller / combined cycle power plant / low and high pressure steam / HRSG / turbine

\section{Introduction}

Having a better technology to produce electricity with high efficiency and electric power production is important. One of these technologies is using absorption cooling system instead of mechanical vapor compression (MVC) cooling system. MVC have a mechanical compressor and they consume some of the electricity produced in Power Plant. Since growing concern about global warming has directed much attention towards natural gas-driven cogeneration systems. The electrical energy consumption for cooling in these spaces is high and also due to the high cost and network requirements to more electricity, it is necessary to use a system with very low power consumption (Fig. 1). As presented in previous works [1-5] the absorption refrigeration systems with thermal generator demonstrate high efficiency with low power consumption, so here, their modeling and performance are investigated. In reference [1] a dual pressure combined cycle based on

\footnotetext{
${ }^{a}$ Corresponding author: Hadizadeh.a@gmail.com
}

a regenerative gas turbine was designed using GateCycle software and the effects of gas-cycle regeneration and gas turbine operative parameters on steam-gas power plants were investigated. Vandani et al. [2] evaluated the impacts of implementation of heat recovery system by genetic algorithm and PSO on the steam power plant. Their results indicated that by using blowdown recovery technique, the net generated power increases $0.72 \%$, whilst energy and exergy efficiency of the system increase by 0.23 and 0.22 , respectively.

In combined cycle power plant, recovery boiler as the interface between the steam cycle and the gas cycle, produces LP and HP steam for the steam turbine by using the exhaust gas from the gas turbine. With respect to this fact the absorption refrigeration systems have heat generator, so part of the steam power, can be delivered to chiller [6]. This process with avoiding the use of fossil fuels and also, with a significant reduction of power consumption by cooling systems, improves energy efficiency and reduces emissions of power planet. A conventional 


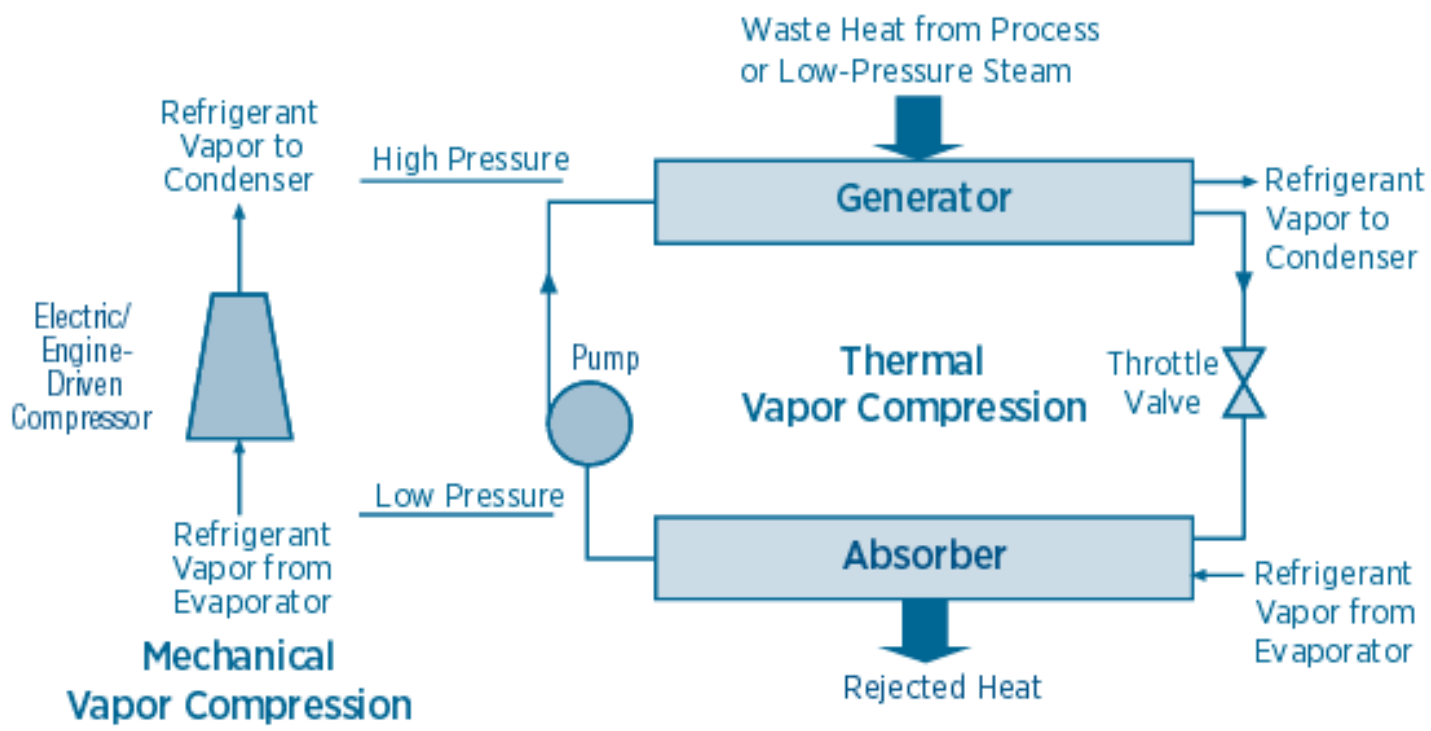

Fig. 1. Comparison of mechanical and thermal vapor compression systems.

mechanical power planet has many problems, such as high initial cost, large installation space and low efficiency. Aurousseau et al. [7] reviewed the control methods of the direct steam generation systems used in line focus on concentrating solar power for reduction of using fossil fuels and improving the energy efficiency.

Mago and Chamra [8] optimized a combined cooling, heating, and power systems following the electric load and the thermal load strategies to reduce primary energy consumption, operation cost, and carbon dioxide emissions reduction. Their results showed that, the optimum primary energy consumption and cost reduction are $7.5 \%$ and $4.4 \%$, respectively. Al-Hawaj [9] studied the absorption refrigeration system and compared it with MVC cooling system used in a single pressure Power Plant. In this investigation, steam needed for the absorption system is extracted at a certain pressure from steam turbine. Enhancement of Power Plant efficiency due to the absorption system was obtained as a result. Darwish [10] replaced a desalination system with absorption water chillers for district air conditioning. Making better use of energy, equipment and more beneficial alternative to using mechanically deriving MVC refrigeration are the results of this study. Najjar [11] and Edera and Kojima [12] studied a cogeneration system whereby portion of GT exhaust heat was used to drive an aqua-ammonia chiller with an evaporator connected to an air pre-cooler inlet supply to the GT compressor, and found an enhancement of about $21 \%$ in Power Plant efficiency. Tichi et al. [13] examined the effects of current and future energy price policies on optimal configuration of combined heat and power and combined cooling, heating, and power systems in Iran, under the conditions of selling and not-selling electricity to utility. They used particle swarm optimization algorithm for tradeoff between cost and energy function. Their results showed that for the same prime mover and with current subsidized prices, in overall these systems require 5 years for capital recovery.

Ahmadi and Toghrae [14] investigated steam cycle of Shahid Montazeri Power Plant of Isfahan with individual unit capacity of 200 MW. They analyzed all cycle equipment individually and calculated the energy efficiency, exergy efficiency, and irreversibility for each of them, by using mass, energy, and exergy balance equations. Their results from the energy analysis showed that $69.8 \%$ of the total lost energy in the cycle occurs in the condenser as the main equipment wasting energy, while exergy analysis introduced the boiler as the main equipment wasting exergy where $85.66 \%$ of the total exergy entering the cycle is lost. Gharneh et al. [15] studied the productivity levels of all steam power plants in Iran. They found that technology, efficiency, and TFP have declined on average and the main factor causing change in productivity is technological change. Therefore, in this investigation PAREHSAR combined cycle power plant with a capacity of 964 megawatt, located in north of Iran is studied. This Power Plant has four GT, four HRSG and two steam turbines that each two HRSG produces steam for one steam turbine. The HRSG is a dual-pressure counter current heat exchanger with supplementary firing. Experimental data show that a portion of LP and HP steam is extracted as an auxiliary steam for heating, ventilation and air conditioning (HVAC) systems and heating tanks in winter, whilst in summer a portion of this steam remains unused. In this paper an innovative absorption chiller heater with auxiliary waste heat recovery and using LP and HP steam of HRSG are utilized to overcome the drawbacks of conventional power planet energy efficiency. The study of temperature and pressure of steam produced shows that these steam conditions are suitable for using in thermal generator of absorption system. This parametric study is investigating the effect of main 


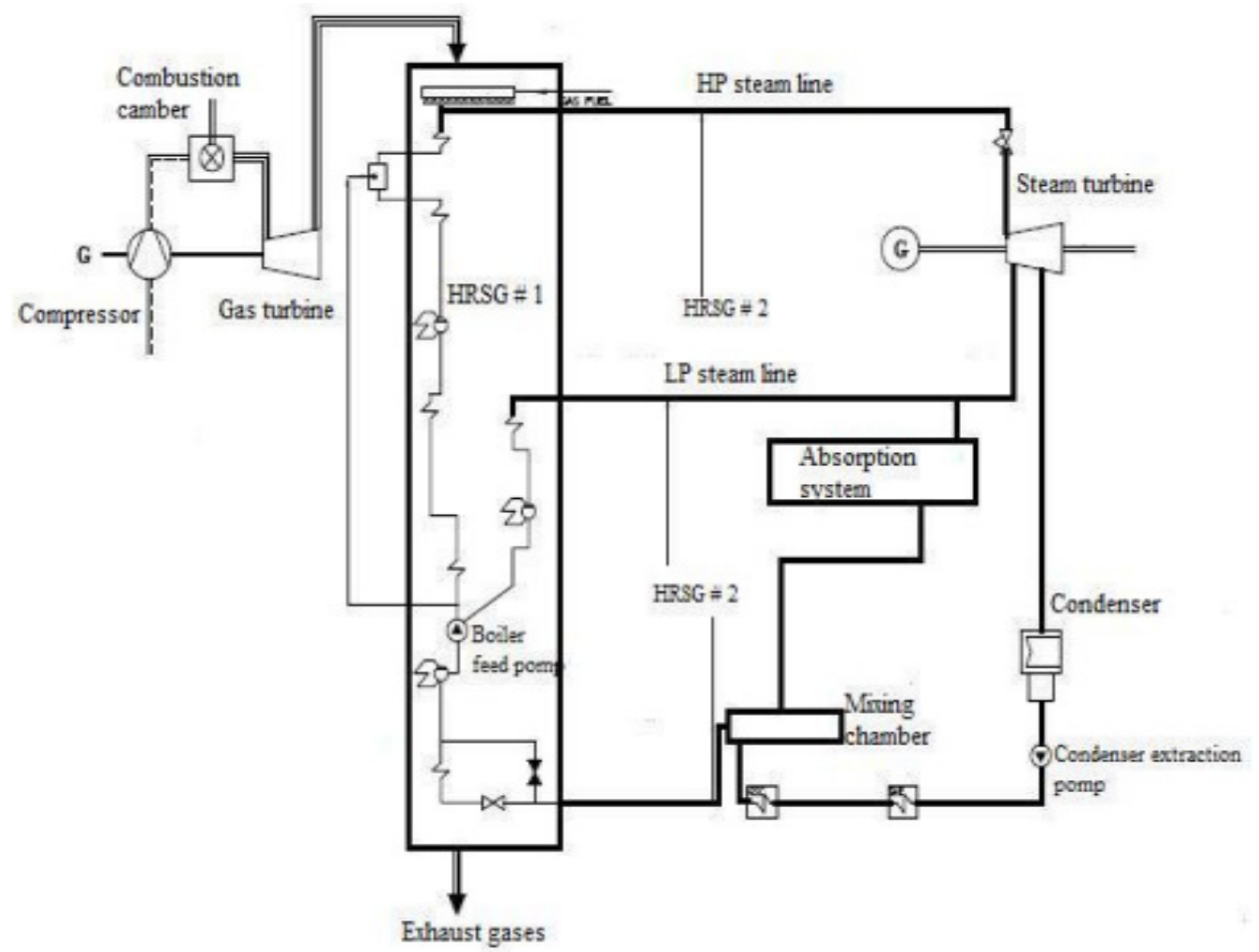

Fig. 2. A combined cycle and absorption refrigeration diagram with steam extraction from LP steam line.

thermodynamic factors [16] on the combined cycle Power Plant efficiency with absorption air conditioning.

\section{System description}

Diagram of the system and its important components are shown in Figure 2. This system indicates a combined cycle consisting of a top gas cycle and a bottom vapor cycle that have a steam extraction from LP steam line. Two cycles are connected to each other by a counter current heat exchanger called heat recovery steam generator, HRSG. The condition of super-heated outlet steam of HRSG is controlled by a combination of a supplementary firing and a control valve disposed at the inlet of the exhaust gas.

When combustion gases that are inside to the HRSG are not sufficient to bring up the steam to the required condition, the supplementary firing unit is turned on by combusting an additional amount of fuel to bring the steam to the design steam condition. If the heat from combustion gases is more than the amount needed, the supplementary firing unit is turned off and the amount of excess heat diverted to the stack. In the steam cycle two types of low pressure (LP) and high pressure (HP) steam are produced for steam turbine. A portion of the LP steam is extracted in order to supply the thermal energy needed for generator of absorption system and the remained steam with a HP steam enters the turbine and after producing the power enters the condenser. The con- densed vapor in the condenser is pumped by condenser pomp to a pressure of mixing chamber so as to mix with the extracted condensed portion coming from the generator, and the total is pumped by HRSG pomp to a higher pressure of the HRSG unit.

\section{Cycle modelling and equations}

In this section, mathematical model of combined cycle power plant with steam extraction for cooling system is provided. For this purpose, four different approaches to the extraction of steam from this cycle are studied, including: using LP and HP steam of HRSG, and using LP and HP steam of Turbine. A parametric study of Energy analysis based on the first law of thermodynamic is performed using MATLAB. The following performance parameters are considered in this study:

$$
\begin{aligned}
U F & =\frac{\left(W_{\mathrm{cc}}\right)_{\mathrm{AB}, \mathrm{LP}}+Q_{\mathrm{Gen}}}{Q_{\mathrm{in}}} \\
\left(\eta_{\mathrm{cc}}\right)_{\mathrm{AB}} & =\frac{\left(W_{\mathrm{cc}}\right)_{\mathrm{AB}, \mathrm{LP}}}{Q_{\mathrm{in}}} \\
\left(\eta_{\mathrm{cc}}\right)_{\mathrm{MVC}} & =\frac{\left(W_{\mathrm{cc}}\right)_{\mathrm{MVC}}}{Q_{\mathrm{in}}} \\
W S A V \% & =\frac{\left(W_{\mathrm{cc}}\right)_{\mathrm{AB}, \mathrm{LP}}-\left(W_{\mathrm{cc}}\right)_{\mathrm{MVC}}}{\left(W_{\mathrm{cc}}\right)_{\mathrm{AB}, \mathrm{LP}}} \times 100
\end{aligned}
$$


A. Hadizadeh et al.: Mechanics \& Industry 18, 213 (2017)

$$
U F_{\mathrm{LP}}=\frac{w_{\mathrm{GT}}-w_{\mathrm{C}}+Z_{1}\left[w_{\mathrm{ST} 1}-w_{\mathrm{P} 2}+X\left(-w_{\mathrm{ST} 1}-w_{\mathrm{P} 1}-\alpha w_{\mathrm{P} 3}\right)\right]+Z_{2}\left(w_{\mathrm{ST} 2}-w_{\mathrm{P} 2}\right)}{\Delta h_{\mathrm{comb}}+Z_{2} \Delta h_{\mathrm{AX}}}
$$

Table 1. PAREHSAR combined cycle design parameters.

\begin{tabular}{cc}
\hline Parameter & Value \\
Gas cycle mass flow rate $\left(\mathrm{Kg} \cdot \mathrm{s}^{-1}\right)$ & 521.01 \\
HP steam mass flow rate $\left(\mathrm{Kg} \cdot \mathrm{s}^{-1}\right)$ & 134 \\
LP steam mass flow rate $\left(\mathrm{Kg} \cdot \mathrm{s}^{-1}\right)$ & 18 \\
HRSG efficiency & 0.7903 \\
Steam design inlet temperature of high pressure $(\mathrm{HP})$ turbine $\left({ }^{\circ} \mathrm{C}\right)$ & 520 \\
Steam design inlet temperature of low pressure $(\mathrm{LP})$ turbine $\left({ }^{\circ} \mathrm{C}\right)$ & 239 \\
HP steam pressure (Bars) & 90 \\
LP steam pressure (Bars) & 8.5 \\
Heat exchanger effectiveness & 0.78 \\
Ambient temperature $\left({ }^{\circ} \mathrm{C}\right)$ & 21 \\
HP steam temperature $\left({ }^{\circ} \mathrm{C}\right)$ & 520 \\
LP steam temperature $\left({ }^{\circ} \mathrm{C}\right)$ & 230 \\
LiBr weak solution concentration $(\%)$ & 64 \\
LiBr strong solution concentration $(\%)$ & 57 \\
MVC coefficient of performance & 8 -saturated \\
\hline
\end{tabular}

where, $U F$ is Utilization factor, $\left(W_{\mathrm{cc}}\right)_{\mathrm{AB}}$ and $\left(W_{\mathrm{cc}}\right)_{\mathrm{MVC}}$ are combined cycle work with absorption and MVC cooling respectively. WSAV\% is Power saving $(\%)$ and $\left(\eta_{\mathrm{cc}}\right)_{\mathrm{AB}}$ and $\left(\eta_{\mathrm{cc}}\right)_{\mathrm{MVC}}$ are combined cycle efficiency with absorption and MVC cooling respectively. Also, the summation of total heat of combustion chamber $\left(Q_{\text {comb }}\right)$ and an auxiliary heat added through the supplementary firing $\left(Q_{\mathrm{Ax}}\right)$ are the heat input $\left(Q_{\text {in }}\right)$. Furthermore, relation between work and heat can be calculated as:

$$
W_{\mathrm{MVC}}=\frac{Q_{\mathrm{E}}}{C O P_{\mathrm{MVC}}}, \quad\left(W_{\mathrm{cc}}\right)_{\mathrm{MVC}}=W_{\mathrm{cc}}-W_{\mathrm{MVC}}
$$

where, $W_{\mathrm{MVC}}$ is a required compressor work for MVC cooling system that for a typical MVC cycle with coefficient of performance, $\mathrm{COP}=2$, is used to provide equivalent cooling load, $Q_{\mathrm{E}}$. Also $W_{\mathrm{cc}}$ is a combined cycle work with no extraction of steam.

Here, equation for the first condition is proposed and for three other cases, the relationships are similar to the first case. So, with considering the $Z_{1}$ and $Z_{2}$ as the mass flow rate ratios of LP and HP steam in the steam cycle to gas in the gas cycle and $X$ as the ratio of mass flow rate of extracted steam for absorption system $\left(M_{\mathrm{Ex}}\right)$ to extracted steam to LP steam $\left(M_{\mathrm{S} 1}\right)$, and replacing in Equations (1) Utilization factor is determined as:

$$
\text { See equation (6) above. }
$$

Hear, $\alpha$ is a parameter obtained by considering the mass and energy analysis on the generator for a fixed concentration ratio, $f$, of strong to weak $\mathrm{LiBr}$ solution, such that:

$$
\alpha=\frac{\Delta h_{\mathrm{Gen}}}{f h_{\mathrm{WS}}+(1-f) h_{\mathrm{R}}-h_{\mathrm{ss}}}
$$

where, $h_{\mathrm{ss}}$ is a strong solution enthalpy and is a weak solution enthalpy of $\mathrm{LiBr}$ and $H_{\mathrm{R}}$ is a refrigerant (water) enthalpy. Also enthalpy difference of steam across the generator is $\Delta h_{\mathrm{Gen}}$. Also, Enthalpy difference of steam due to auxiliary heating in HRSG, $\Delta h_{\mathrm{Ax}}$, can be defined as follows:

$$
\Delta h_{\mathrm{AX}}=\left\{\begin{array}{l}
0, \quad T_{\mathrm{SHRSG}} \geqslant T_{\mathrm{SDI} 2} \\
\Delta h_{\mathrm{SDI} 2}-\frac{\varepsilon \Delta h_{\mathrm{GMX}}-Z_{1} \Delta h_{\mathrm{SDI} 1}}{Z_{2}}, T_{\mathrm{SHRSG}} \leqslant T_{\mathrm{SDI} 2}
\end{array}\right.
$$

where $T_{\mathrm{SDI} 2}$ is a steam design inlet temperature of high pressure (HP) turbine and $T_{\text {SHRSG }}$ is a calculated HRSG HP steam exit temperature. $\Delta h_{\mathrm{SDI} 1}, \Delta h_{\mathrm{SDI} 2}$ and $\Delta h_{\mathrm{GMX}}$ respectively are enthalpy difference of steam between inlet to HRSG and the steam design inlet to the LP turbine, enthalpy difference of steam between inlet to HRSG and the steam design inlet to the HP turbine and maximum enthalpy difference of gas across the HRSG with no supplementary heating. Also heat exchanger effectiveness is $\varepsilon$.

In obtaining this equation is assumed that combustion gases across the HRSG, even if insufficient, are able to deliver LP steam to the desired condition. Therefore, assuming constant LP steam conditions, with reducing of HP steam temperature, supplementary firing unit is turned on. In other words if the heat of combustion gases can't deliver the HP steam exit temperature of HRSG to the steam design inlet temperature of HP turbine, supplementary unit is turned on. So, Equations (2) and (3) can be expanded as:

\section{See equations (9) and (10) next page.}

In these equations, $W_{\mathrm{P} 1}$ is work per unit mass of condenser pomp, $W_{\mathrm{P} 2}$ is work per unit mass of HRSG pomp and $W_{\mathrm{P} 3}$ is work per unit mass of $\mathrm{LiBr}$ solution pomp. Finally by substituting these equations in Equation (4), power saving ratio calculated as following:

See equation (11) next page. 


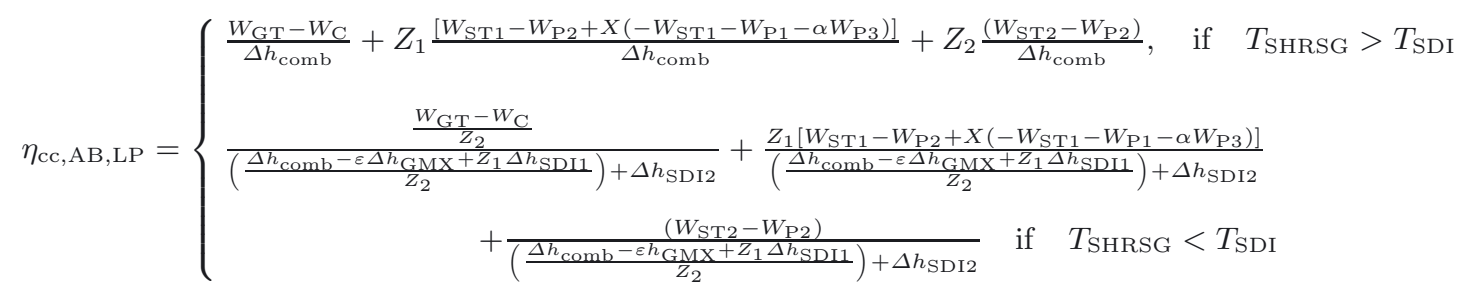

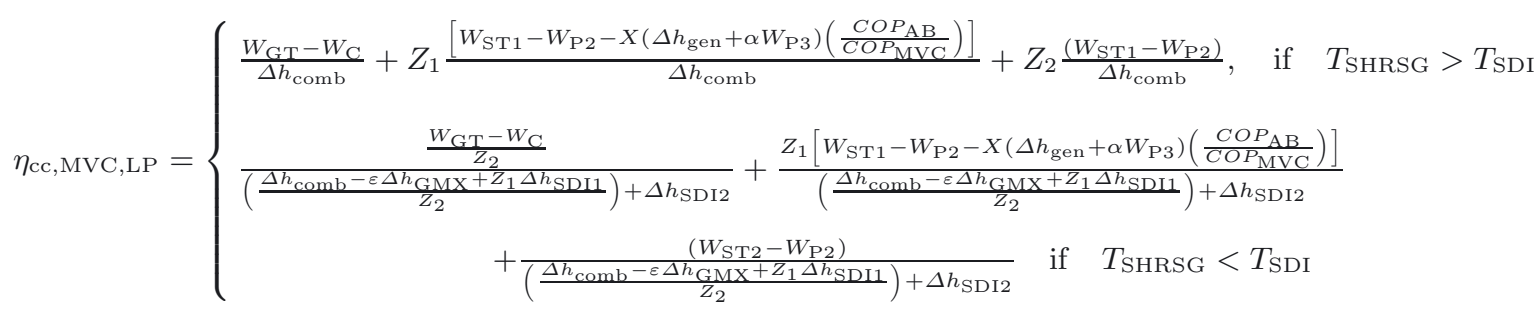

$$
W S A V_{\mathrm{LP}}=\frac{X\left[-W_{\mathrm{ST} 1}-W_{\mathrm{P} 1}-\alpha W_{\mathrm{P} 3}\left(\left(\frac{C O P_{\mathrm{AB}}}{C O P_{\mathrm{MVC}}}\right)-1\right)+\Delta h_{\mathrm{gen}}\left(\frac{C O P \mathrm{AB}}{C O P_{\mathrm{MVC}}}\right)\right]}{\frac{W_{\mathrm{GT}}-W_{\mathrm{C}}+Z_{2}\left(W_{\mathrm{ST} 2}-W_{\mathrm{P} 2}\right)}{Z_{1}}+\left[W_{\mathrm{ST} 2}-W_{\mathrm{P} 2}+X\left(-W_{\mathrm{ST} 1}-W_{\mathrm{P} 1}-\alpha W_{\mathrm{P} 3}\right)\right]}
$$

In all the previous equations, $W_{\mathrm{ST} 1}, W_{\mathrm{ST} 2}, W_{\mathrm{GT}}$ and $W_{\mathrm{C}}$ are respectively a work per unit mass of LP turbine, HP turbine, gas turbine (GT) and compressor. The designed parameters of PAREHSAR combined cycle are presented in Table 1.

\section{Results and discussion}

In this section thermodynamic power planet model is simulated and four different approaches to the extraction of steam from the combined power plant cycle (LP and HP-HRSG and Turbine) for cooling are evaluated. In addition, the effects of various parameters on power plant efficiency with absorption cooling system are investigated which include, vapor extraction rates, changes in the steam cycle to cycle gas flow rate, temperature turbine inlet design pressure, design temperature LP turbine inlet compressor pressure ratio.

\subsection{Using LP steam of HRSG}

The effect of LP steam to gas flow rate on the efficiency of the power plant with absorption system in various steam extraction ratios is illustrated in Figures 3 and 4.

Results demonstrate that efficiency of combined cycle power plant was little affected by steam extraction ratios variation. It is obvious that, generated power of LP turbine has been affected by steam extraction, and given that, less steam enters the turbine consequently efficiency decreases slightly. As shown in this graph the maximum reduction in the efficiency occurs when the extraction ratio is 0.08 . It is founded from Figure 3 that the optimal mass flow ratio is $Z_{2}=0.129$. With increasing the mass flow ratio from optimum value, the HRSG outlet temperature decreases than inlet designed temperature. So, in order to increase the steam temperature to the turbine inlet designed conditions, the auxiliary ignition is turned on and with the consumption of additional fuel, the total efficiency is decreased.

Figures 5 and 6 show the effect of steam extraction on utilization factor of power plant. Utilization factor actually is a factor that shows how much of extracted steam heat can be used. As can be seen, enhancement of utilization factor up to is the same and in this point is about $0.29 \%$. However, after this point with increasing of this enhancement is less.

Effect of inlet LP and HP turbine design temperature on combined cycle efficiency is indicated in Figures 7 and 8. Rising these temperatures increase the auxiliary heat input in the HRSG and steam turbine power output. According to Figure 7 it can be seen that inlet LP turbine design temperature has little effect on combined cycle efficiency. By increasing the temperature from $200{ }^{\circ} \mathrm{C}$ to $350{ }^{\circ} \mathrm{C}$ enhancement of efficiency up to $Z_{2}=0.127$ is the same and in this point is $0.56 \%$. But after it this enhancement is reduced as in $Z_{2}=0.129$ is $0.33 \%$.

As it shown in Figure 8 inlet HP turbine design temperature has significant effect on combined cycle efficiency. By increasing the temperature from $450{ }^{\circ} \mathrm{C}$ to $600{ }^{\circ} \mathrm{C}$ efficiency continuously increases as most of this increase is $5.2 \%$ that occurs in $Z_{2}=0.121$. Also in $Z_{2}=0.129$ it is equal to $4.05 \%$. But after it, this enhancement is again increased as in $Z_{2}=0.5$ is $5.3 \%$.

Figure 9 shows the effect of MVC and absorption cooling system on combined cycle efficiency at 0.08 steam extraction ratio. As illustrated in this figure the combined cycle power plant with MVC cooling has a lower efficiency than for combined cycle power plant with absorption cooling providing equal thermal load. As it shown in Figure 9 
A. Hadizadeh et al.: Mechanics \& Industry 18, 213 (2017)

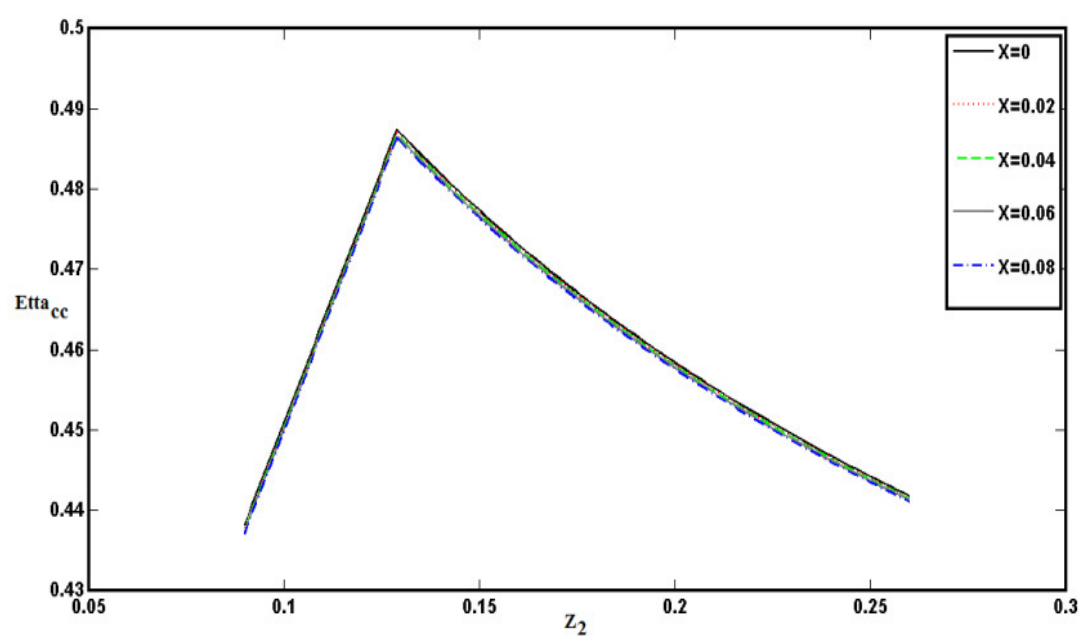

Fig. 3. Effect of LP steam to gas flow rate on the efficiency.

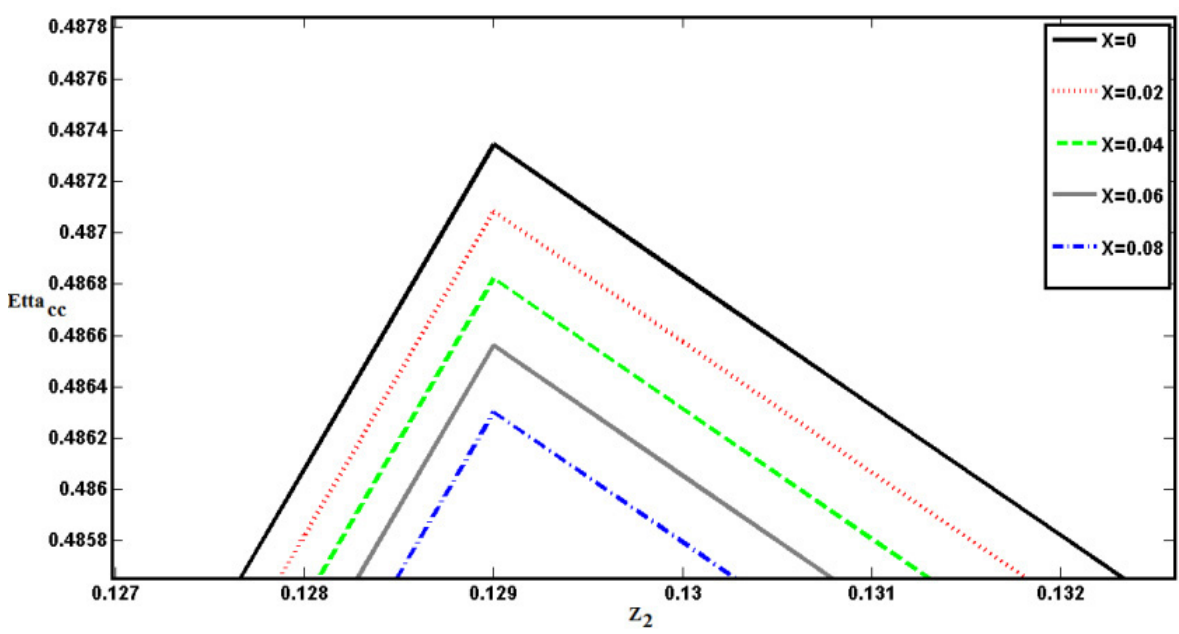

Fig. 4. Effect of LP steam to gas flow rate on the efficiency at $Z_{2}=0.129$.

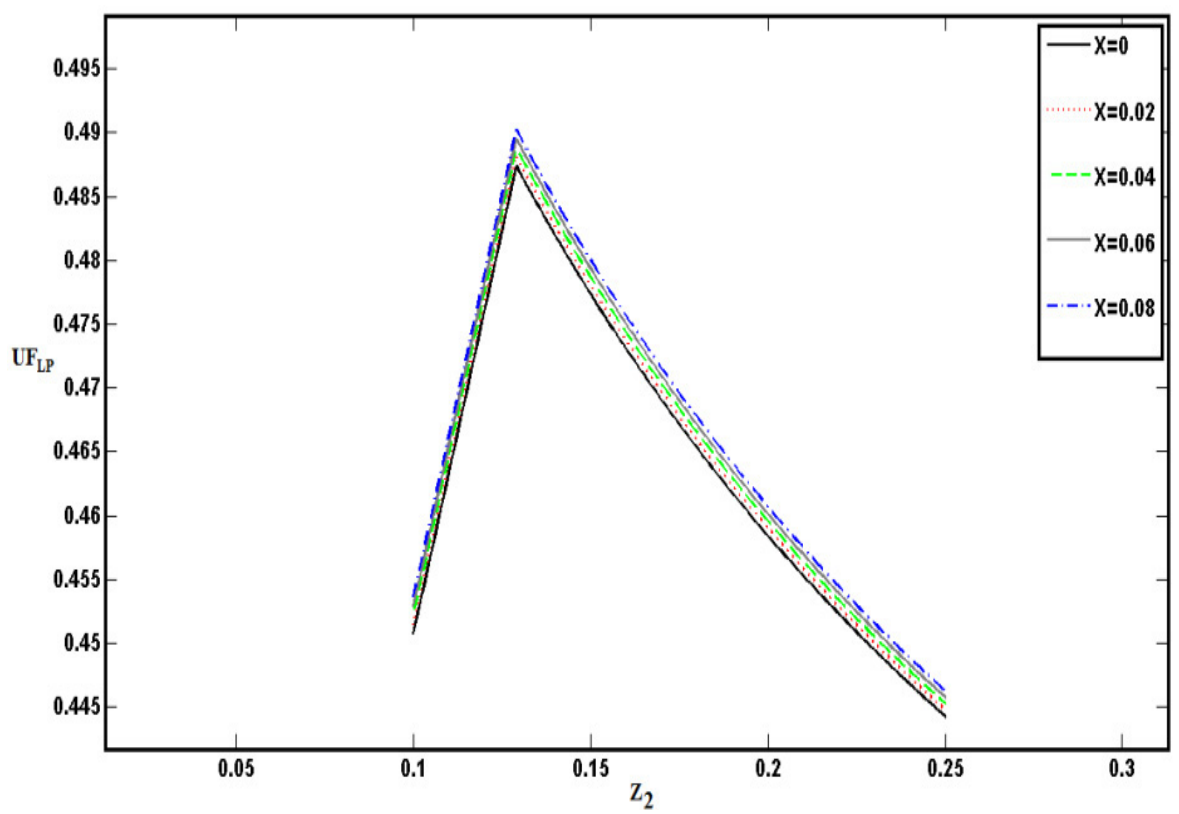

Fig. 5. Steam extraction effect on combined cycle utilization factor. 


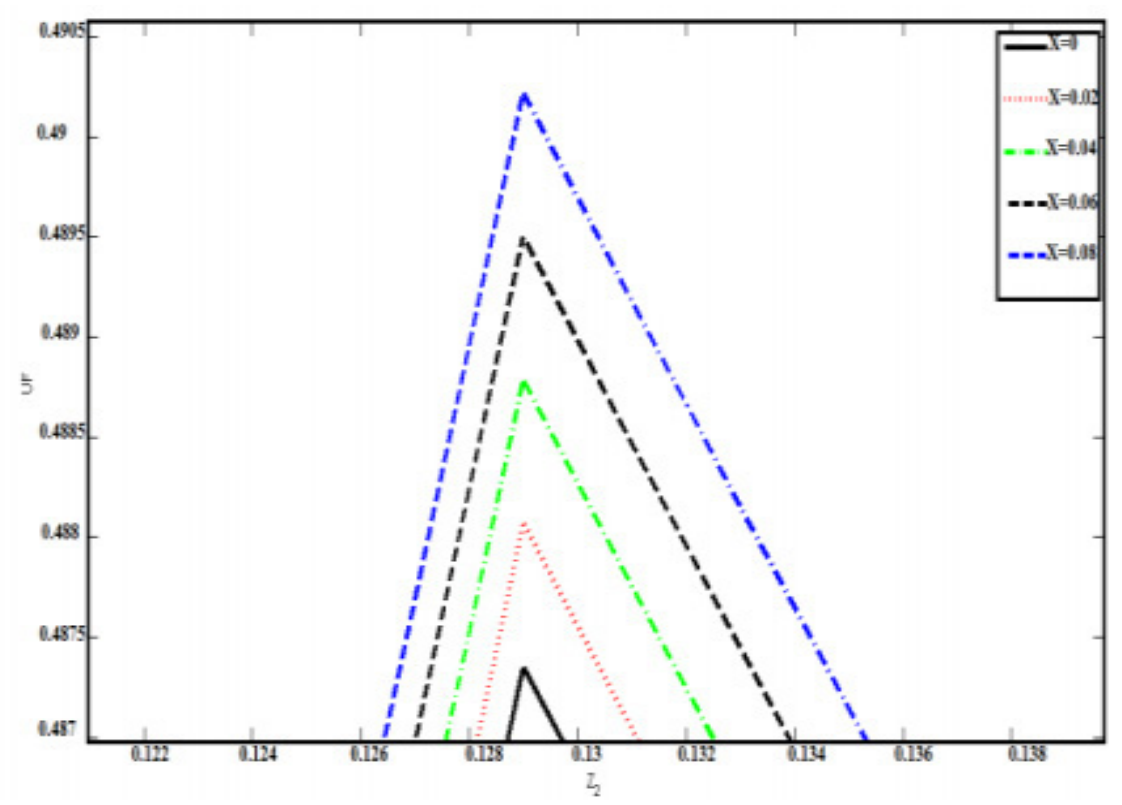

Fig. 6. Effect of steam extraction on utilization factor at $Z_{2}=0.129$.

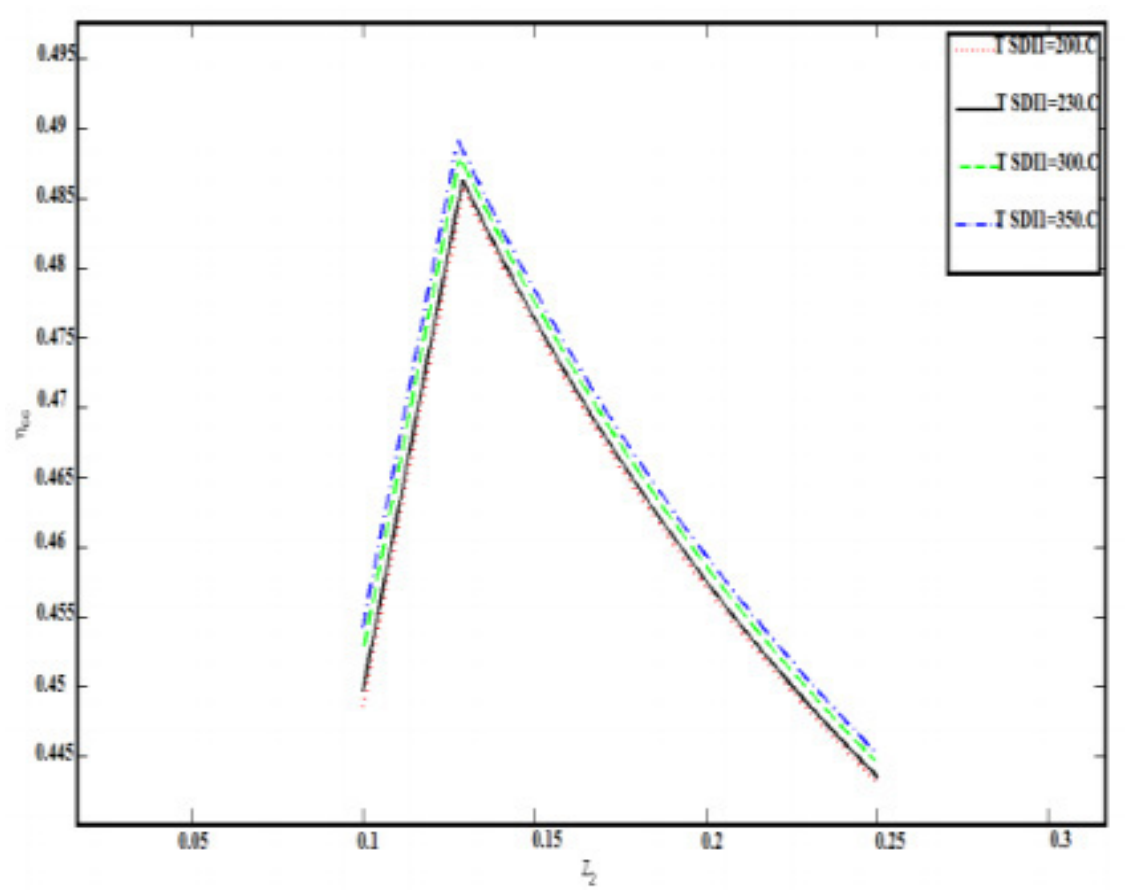

Fig. 7. Effect of inlet LP turbine design temperature on combined cycle efficiency.

at point $Z_{2}=0.5$ efficiency difference is $0.1 \%$. In other words by using of absorption cooling system in power plant instead of MVC cooling system, $0.1 \%$ efficiency savings will occur.

Power saving percent of combined cycle power plant with absorption cooling versus MVC cooling system was illustrated in Figure 10. As shown the amount of power saving increases with reducing of $Z_{2}$. Since extracted steam flow rate for absorption cooling system extract from LP steam line therefore by reducing the amount of
HP steam and $Z_{2}$, LP steam role in producing power for power plant is important. So steam extraction from LP steam line is important and then as a result more power can be saved.

\subsection{Using HP steam of HRSG}

In this case, small part of HP system of HRSG is used in cooling systems for providing required thermal energy. The effect of HP steam to gas flow rate on the efficiency 


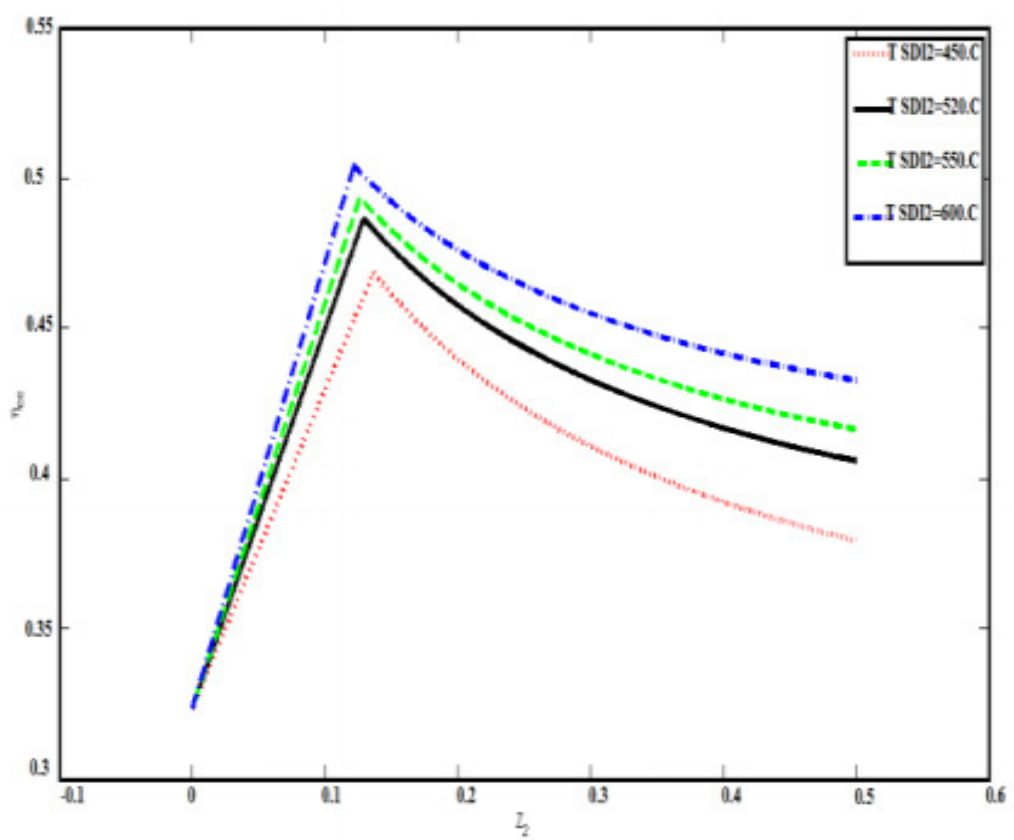

Fig. 8. Effect of inlet HP turbine design temperature on combined cycle efficiency.

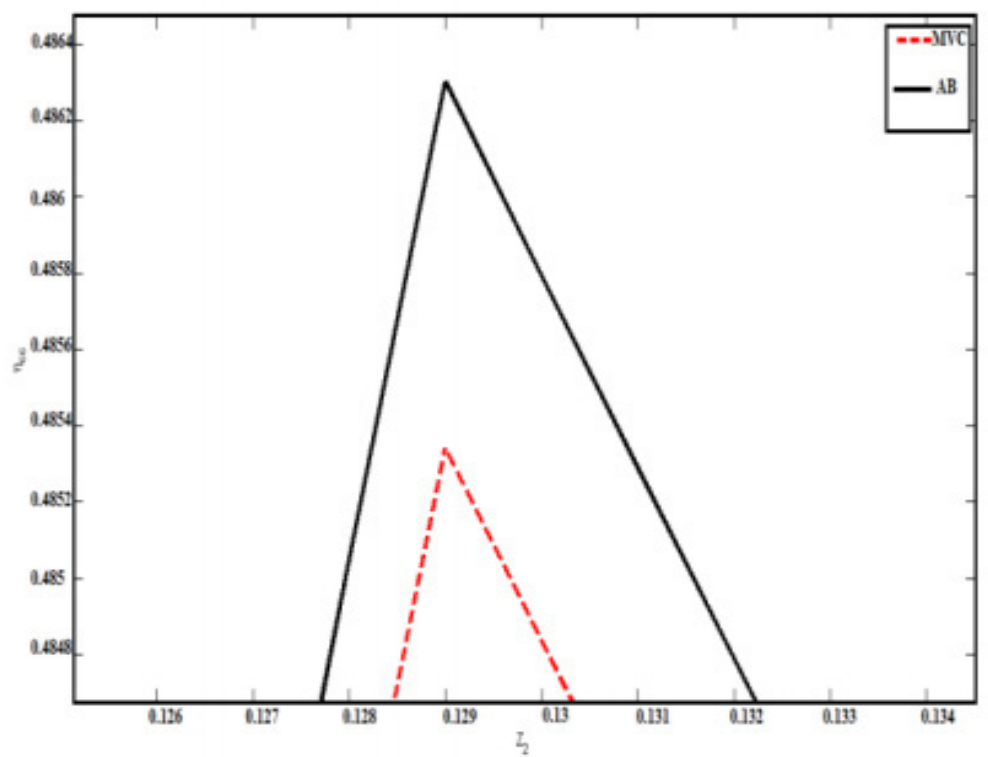

Fig. 9. Effect of MVC and absorption cooling on combined cycle efficiency at 0.08 steam extraction.

and utilization factor of the power plant with absorption system in various steam extraction ratios is illustrated in Figures 11 and 12 respectively. As it can be seen, the variation of efficiency and utilization factor versus to the ratio of HP steam extraction is almost linear, whilst its optimal rate for both parameters is $Z_{2}=0.129$.

Power saved variation due to ratio of HP steam to gas flow rate of gas in various steam extraction ratios is illustrated in Figure 13. It is founded from Figure 13 that the amount of saved power at optimal ratio of HP steam rate to flow rate of gas $\left(Z_{2}=0.129\right)$ is $0.028 \%$, whereas with increasing $Z_{2}$ to 0.7 , the power saved ratio increased up to $0.061 \%$.

Furthermore, the effects of designed inlet temperature of LP turbine on utilization factor illustrated in Figure 14. An increase in designed inlet temperature of low pressure turbine results in increasing the power by providing auxiliary heat of HRSG.

\subsection{Comparison of steam extraction approaches}

In this section, the effectiveness of proposed methods (LP and HP steam of HRSG and turbine) is evaluated 
A. Hadizadeh et al.: Mechanics \& Industry 18, 213 (2017)

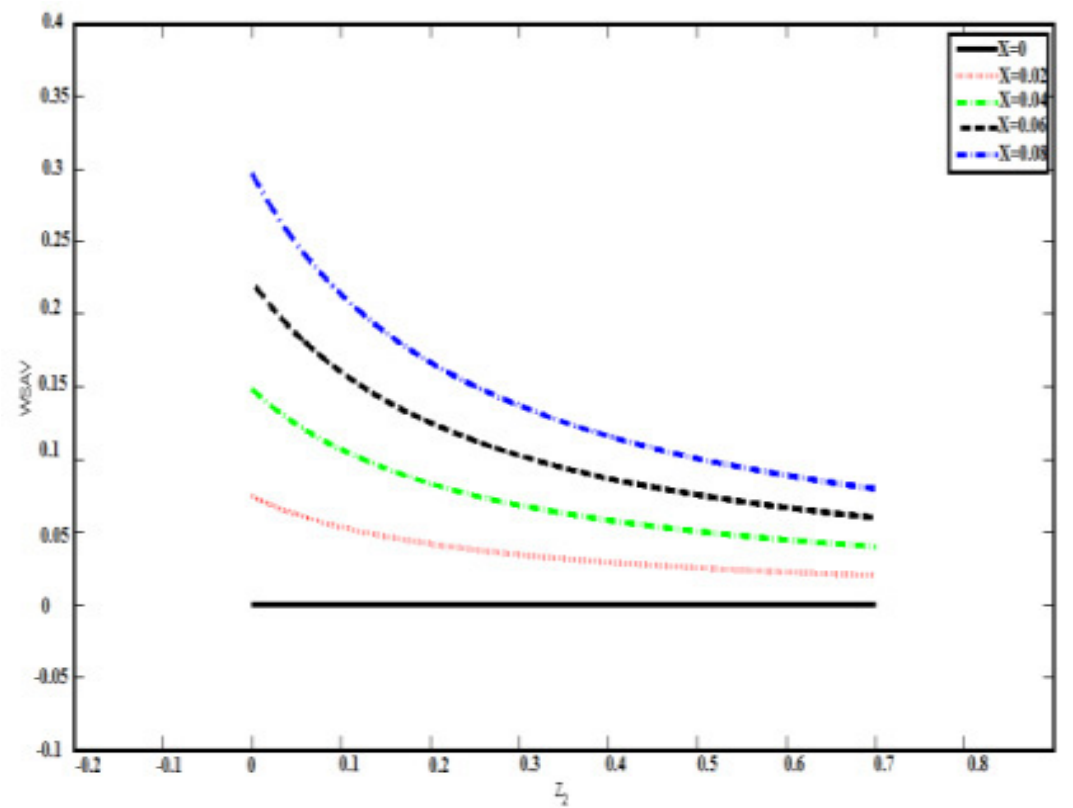

Fig. 10. Power saving percent of combined cycle power plant with absorption cooling versus MVC.

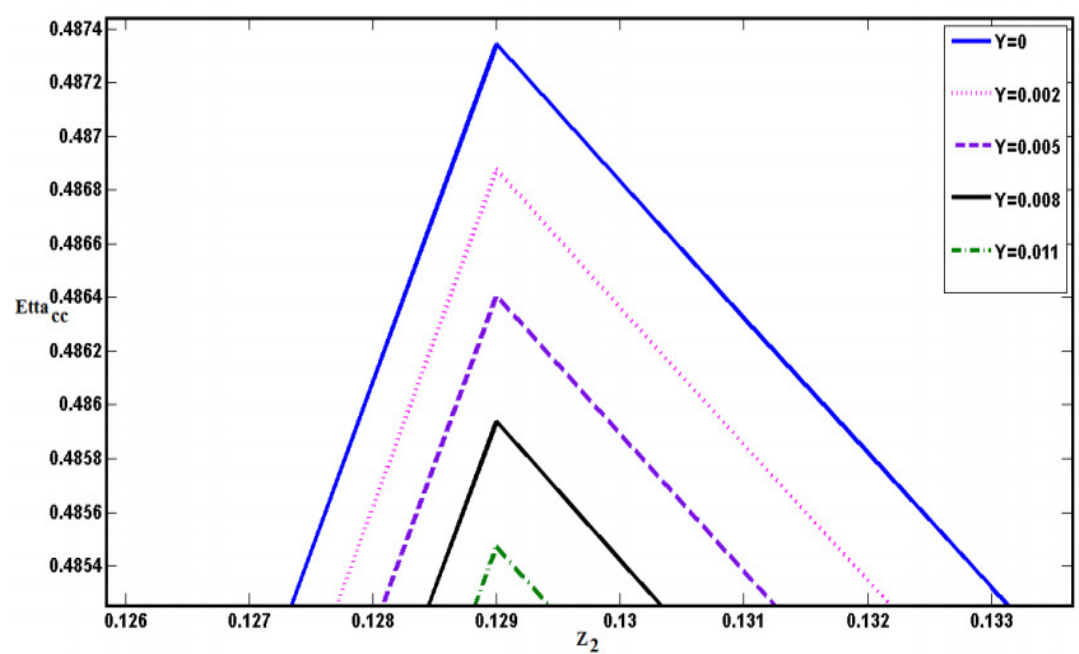

Fig. 11. Effect of HP steam to gas flow rate on the efficiency.

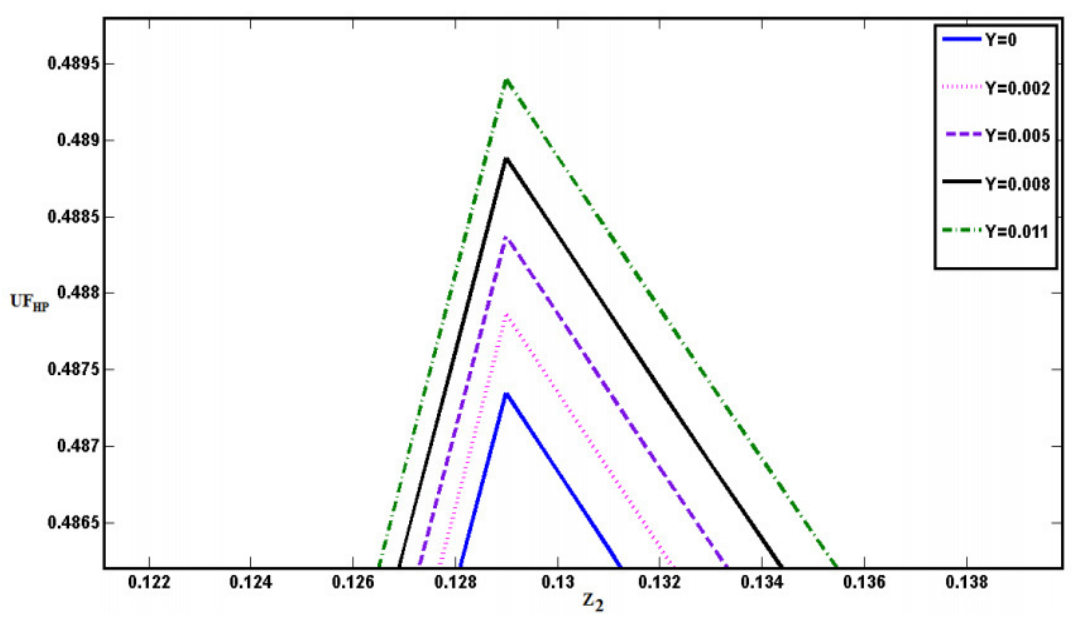

Fig. 12. Effect of HP steam to gas flow rate on the utilization factor. 
A. Hadizadeh et al.: Mechanics \& Industry 18, 213 (2017)

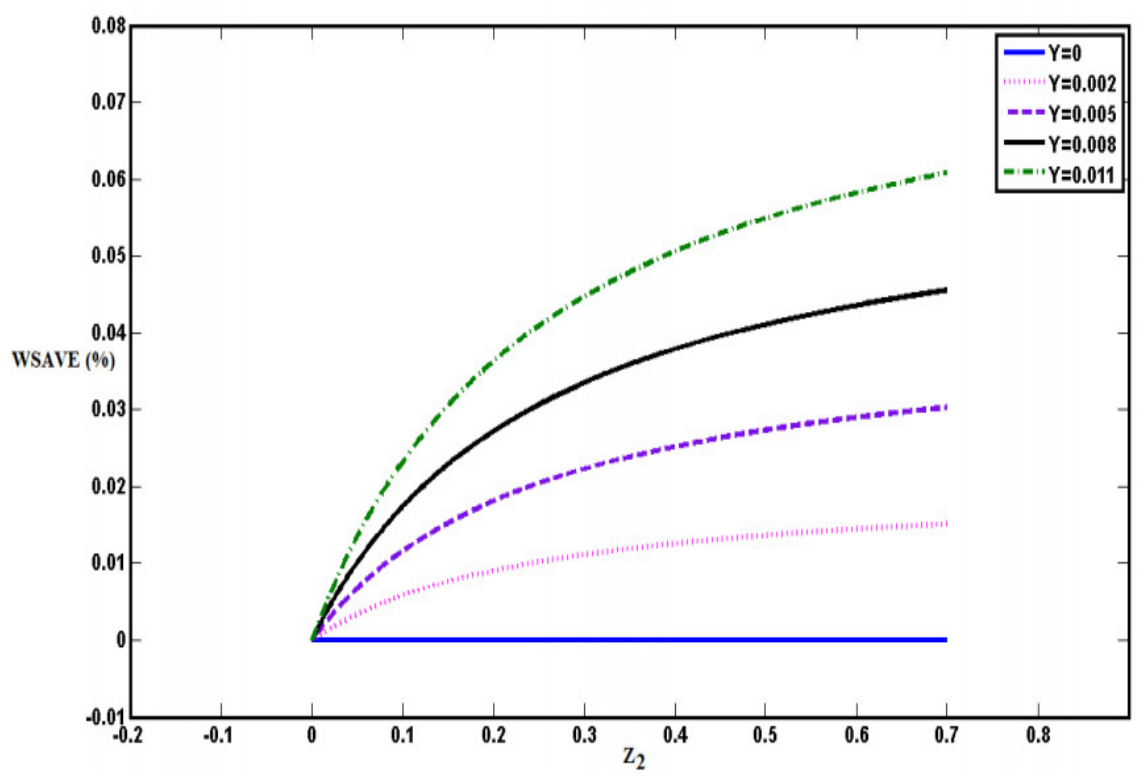

Fig. 13. Effect of HP steam to gas flow rate on the power save ratio.

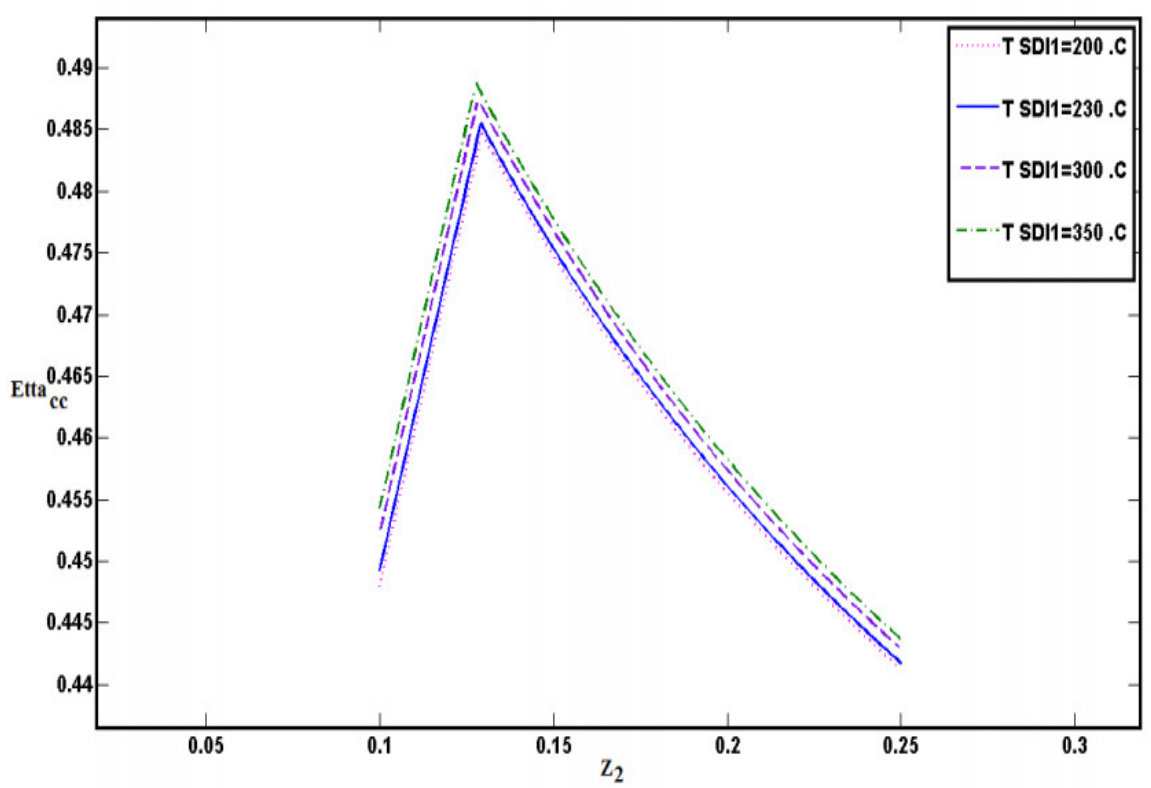

Fig. 14. Effects of designed inlet temperature of LP turbine on utilization factor.

and then the best approach for aspects of power saving and efficiency improving for combined cycle power plant is determined.

Figures 15 and 16 show the effect of each of the proposed approaches on energy efficiency and utilization factor of power planet with the absorption cooling system. Results indicate that steam extraction of HP turbine approach is the Most Efficient Method. However, steam extraction of HP HRSG demonstrates the lowest efficiency. In overall, it can be concluded that steam extraction of turbine is more effective than HRSG. Since in the steam extraction of turbine approaches, this steam is expanded and carried out some positive works, then extracted from turbine. Whereas in the HRSG approaches, part of the steam, which has potential of working, extracted directly. In addition it is founded from results that HP steam extraction improves the efficiency more than LP steam extraction Because HP steam with the 31 bar pressure and $521{ }^{\circ} \mathrm{C}$ delivers to turbine, and after exposition and generating power, the partial part of it extracted from turbine terminal section extracted, whilst, LP steam with the 1.5 bar pressure, without expansion and generating the power, is extracted.

Figure 17 depicts the proposed approaches effects on saved power ratio. Results demonstrate that, despite the upward trend of HP-HRSG, it has the least amount of 

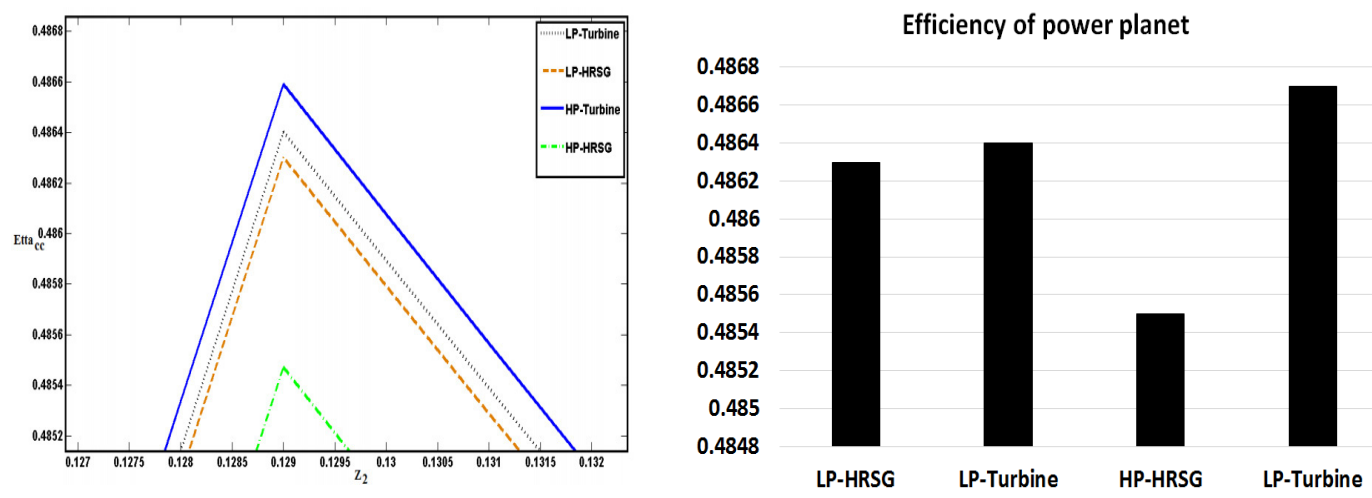

Fig. 15. Comparison of the effect of the proposed approaches on energy efficiency.
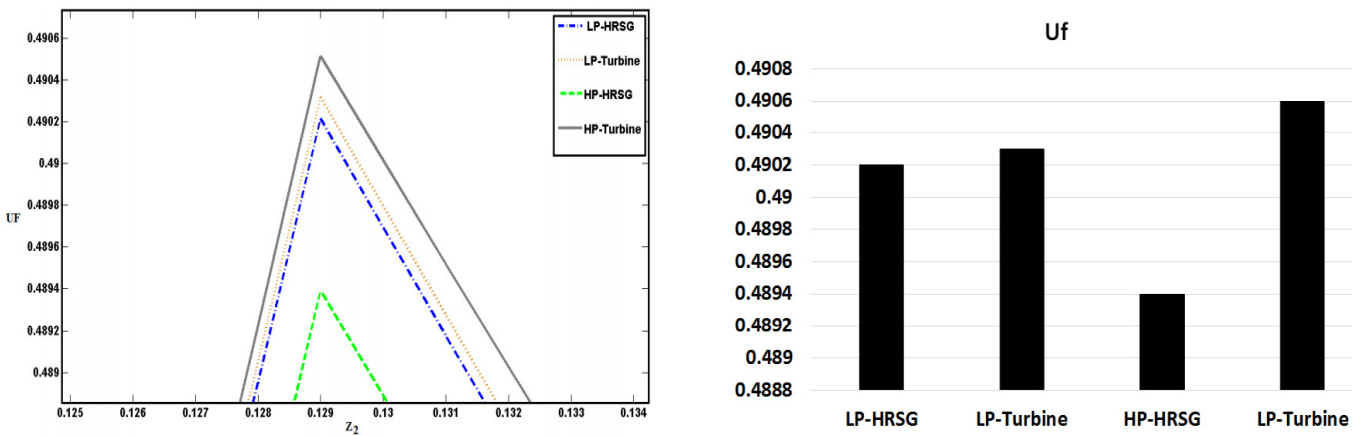

Fig. 16. Comparison of the effect of the proposed approaches on the utilization factor.
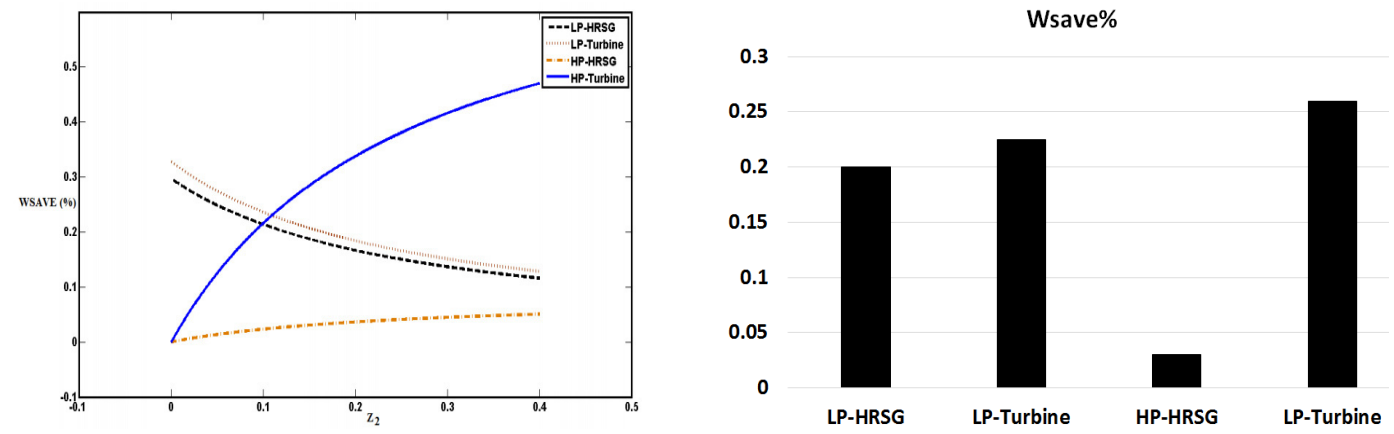

Fig. 17. Comparison of the effect of the proposed approaches on the saved power ratio.

storage capacity for various values of $Z_{2}$. Also, it is obvious that with increasing the $Z_{2}$ values, LP approaches have the downward trend. Up to point $Z_{2}=0.11$, LP-Turbine approach is preferable, however, with increasing $Z_{2}$ values, HP-turbine method has the most ability to save power.

\section{Conclusions}

In this paper, a combined cycle power plant with absorption cooling system has been studied. For improving the energy efficiency and performance of proposed power planet, four methods based on LP-HRSG, LP-Turbine, HP-HRSG and HP-Turbine approaches were proposed and their effects on various parameters of power planet evaluated. In addition, the effect of some parameters such as steam to gas mass flow rate ratio, fraction of steam extraction from the exhaust of LP line in HRSG for the generator of absorption chillers and inlet LP and HP steam turbine temperature on the performance of present power plant have been studied. Results indicated that, with the using of each of these approaches for cooling of the power planet, the energy efficiency of system has been improved. Finally, the parametric analysis results were summarized as:

- Optimal value of the HP steam to gas mass ratio is $Z_{2}=0.129$, which results in maximum efficiency and utilization factor.

- Power planet efficiency is more sensitive to variation of HP steam turbine inlet design temperature than LP 
one. In other words, with increasing the HP steam turbine inlet design temperature, the efficiency and utilization factors increase significantly, while they were remained almost constraint with the increasing the LP one.

- A combined cycle power plant with MVC cooling yields significantly more power than a combined cycle power plant with absorption cooling.

- Compressor pressure ratio changes from 8 to 14 bar, increased energy efficiency by $5 \%$ in the optimal HP steam to gas mass ratio.

- The fraction of power saving asymptotically decreases with increase in HP steam to gas mass ratio exceeding the optimum value.

- The HP-Turbine was more effective than the other approaches for improving the power planet performance.

\section{References}

[1] R. Carapellucci, L. Giordano, Studying the effects of combining internal and external heat recovery on technoeconomic performances of gas-steam power plants, Energy Convers. Manag. 107 (2016) 34-42

[2] A. Mohammadikhoshkar, M. Bidi, F. Ahmadi, Exergy analysis and evolutionary optimization of boiler blowdown heat recovery in steam power plants, Energy Convers. Manag. 106 (2015) 1-9

[3] A. Huicochea, W. Rivera, G. Gutiérrez-Urueta, J. Carles, A. Coronas, Thermodynamic analysis of a trigeneration system consisting of a micro gas turbine and a double effect absorption chiller, Appl. Thermal Eng. 31 (2011) 3347-3353

[4] S.O. Oyedepo, O. Kilanko, Thermodynamic Analysis of a Gas Turbine Power Plant Modeled with an Evaporative Cooler, Int. J. Thermodynam. 17 (2014) 14-20

[5] K. Banasiak, A. Hafner, T. Andresen, Experimental and numerical investigation of the influence of the two-phase ejector geometry on the performance of the R744 heat pump, Int. J. Refrigeration 35 (2012) 1617-1625

[6] M. Sharma, O. Singh, Exergy analysis of dual pressure HRSG for different dead states and varying steam generation states in gas/steam combined cycle power plan, Appl. Thermal Eng. 93 (2016) 614-622
[7] A. Aurousseau, V. Vuillerme, J.J. Bezian, Control systems for direct steam generation in linear concentrating solar power plants - A review, Renewa. Sustain. Energy Rev. 56 (2016) 611-630

[8] P.J. Mago, L.M. Chamra, Analysis and optimization of CCHP systems based on energy, economical, and environmental considerations, Energy Buildings 41 (2009) 10991106

[9] O. Hawaja, H. AL-Mutairi, A combined power cycle with absorption air conditioning, Energy 32 (2007) 971-982

[10] M.A. Darwish, New idea for co-generation power desalting plants due to abandoned MSF desalination process, Desalination 134 (2001) 221-230

[11] Y.S.H. Najjar, Enhancement of performance of gas turbine engines by inlet air cooling and cogeneration system, J. Appl. Thermal Eng. 16 (1996) 163-173

[12] M. Edera, H. Kojima, Development of new gas absorption chiller heater-advanced utilization of waste heat from gasdriven co-generation systems for air-conditioning, Energy Convers. Manage. 43 (2002) 1493-501

[13] S.G. Tichi, M.M. Ardehali, M.E. Nazari, Examination of energy price policies in Iran for optimal configuration of CHP and CCHP systems based on particle swarm optimization algorithm, Energy Policy 38 (2010) 6240-6250

[14] G.R. Ahmadi, D. Toghraie, Energy and exergy analysis of Montazeri Steam Power Plant in Iran, Renew. Sustain. Energy Rev. 56 (2016) 454-463

[15] N.S. Gharneh, A. Nabavieh, D. Gholamiangonabadi, M. Alimoradi, Productivity change and its determinants: Application of the Malmquist index with bootstrapping in Iranian steam power plants, Utilities Policy 31 (2014) $114-120$

[16] J.C. Bruno, A. Valero, A. Coronas, Performance analysis of combined microgas turbines and gas fired water $/ \mathrm{LiBr}$ absorption chillers with post-combustion, Appl. Thermal Eng. 25 (2005) 87-99 